\section{Key Words}

asymmetric epoxidation enantioreversal polymers

\title{
Molecular Weight Induced Enantioreversal in Sharpless Asymmetric Epoxidation
}

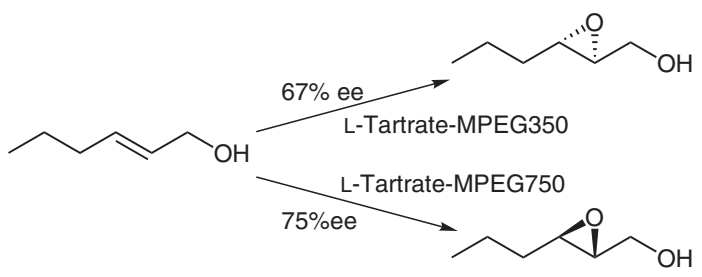

Significance: The molecular weight of the poly(ethylene glycol) monomethyl ether (MPEG) can reverse the enantioselectivity for Sharpless epoxidation. A relatively narrow molecular weight range of 800 is sufficient to provide the enantioreversal.
Comment: While the Sharpless asymmetric epoxidation is one of the most powerful synthetic tools, this finding stands to expand on this reaction. So far, various mechanistic investigations are reported for this important transformation. This paper provides completely new insights for the mechanism. The observed enantioreversal was proposed to occur as a result of 2:1 titaniumligand complex, as opposed to the 2:2 titaniumligand complex of normal Sharpless asymmetric epoxidation. 